\title{
Perineal descent and patients' symptoms of anorectal dysfunction, pelvic organ prolapse, and urinary incontinence
}

\author{
Suzan R. Broekhuis • Jan C. M. Hendriks • \\ Jurgen J. Fütterer • Mark E. Vierhout • \\ Jelle O. Barentsz $\cdot$ Kirsten B. Kluivers
}

Received: 20 July 2009 / Accepted: 1 January 2010 / Published online: 5 February 2010

(C) The Author(s) 2010. This article is published with open access at Springerlink.com

\begin{abstract}
Introduction and hypothesis The aim of this dynamic magnetic resonance (MR) imaging study was to assess the relation between the position and mobility of the perineum and patients' symptoms of pelvic floor dysfunction.

Methods Patients' symptoms were measured with the use of validated questionnaires. Univariate logistic regression analyses were used to study the relationship between the questionnaires domain scores and the perineal position on dynamic MR imaging, as well as baseline characteristics (age, body mass index, and parity).

Results Sixty-nine women were included in the analysis. Only the domain score genital prolapse was associated with the perineal position on dynamic MR imaging. This association was strongest at rest.

Conclusions Pelvic organ prolapse symptoms were associated with the degree of descent of the perineum on dynamic MR imaging. Perineal descent was not related to anorectal and/or urinary incontinence symptoms.
\end{abstract}

S. R. Broekhuis $(\square) \cdot$ M. E. Vierhout $\cdot$ K. B. Kluivers 791 Department of Obstetrics and Gynecology, Radboud University Nijmegen Medical Centre, P.O. Box 9101, 6500 HB Nijmegen, The Netherlands e-mail: S.Broekhuis@obgyn.umcn.nl

J. C. M. Hendriks

Department of Epidemiology,

Radboud University Nijmegen Medical Centre,

Nijmegen, The Netherlands

J. J. Fütterer · J. O. Barentsz

Department of Radiology,

Radboud University Nijmegen Medical Centre,

Nijmegen, The Netherlands
Keywords Dynamic MR imaging · Pelvic floor . Perineal descent $\cdot$ Prolapse $\cdot$ Urinary incontinence . Symptoms

\section{Introduction}

The descending perineum syndrome was first described in 1966 by Parks et al. [1]. Typically, the syndrome is described as ballooning of the perineum several centimeters below the bony outlet of the pelvis during strain, although descent can also occur at rest.

One of the main causes is thought to be excessive and repetitive straining. This straining forces the anterior rectal wall to protrude into the anal canal and creates a sensation of incomplete defecation and weakness of the pelvic floor musculature. In turn, this causes more straining, and a vicious cycle is established $[1,2]$. Other possible causes reported are weakness of the muscles of the pelvic floor caused by either the neuropathic degeneration of muscle that accompanies old age [3-5], or trauma to the pelvic floor muscles or their nerve supply during pregnancy and childbirth $[4,6,7]$.

Abnormal perineal descent has been described in relation to a variety of anorectal disorders such as constipation, fecal incontinence, obstructed defecation, and rectal or pelvic pain. A systematic review of these clinical studies, however, did not show an association of perineal descent with constipation [8-10] and rectal or pelvic pain [10, 11], and the existing data on the association of perineal descent with fecal incontinence [9, 10, 12, 13] and obstructed defecation $[14,15]$ were conflicting. Only few papers have reported on the relation of perineal descent with symptoms of pelvic organ prolapse and stress urinary incontinence $[11,16,17]$. In these studies, prolapse symptoms seemed to 
be associated with the degree of perineal descent, whereas an association with stress urinary incontinence symptoms was unlikely.

In the urogynecological literature, perineal descent has not been extensively studied. The clinical implication of the condition and the relation to patients' symptoms is still unknown. As a consequence, there is no consensus whether diagnosis and treatment of perineal descent should be done at all. The aim of this dynamic magnetic resonance (MR) imaging study was to assess the relation between the position and mobility of the perineum with patients' symptoms of pelvic floor dysfunction using standardized questionnaires.

\section{Materials and methods}

This observational study was performed at the Radboud University Nijmegen Medical Centre, the Netherlands. The center is a national tertiary referral center for women with pelvic organ dysfunctions. The study period was from September 2005 through January 2008. Inclusion criteria were consecutive women with pelvic organ dysfunction who had dynamic MR imaging in the inclusion period and had returned the questionnaires Urogenital Distress Inventory (UDI) and Defecatory Distress Inventory (DDI). MR imaging was performed as part of routine clinical practice in patients with recurrent prolapse, especially in the posterior compartment, and in case the patient's complaints did not correspond with clinical findings. In the Netherlands, the Working Party on Pelvic Floor and Urogynecology of the Dutch Society of Obstetrics and Gynecology recommends each urogynecological center to assess the presence and the bother of pelvic floor dysfunction by taking a careful history and use of the UDI and the DDI. These questionnaires are handed out to all patients with urogynecological symptoms during intake and are completed and returned immediately or by return envelope.

The study was submitted to and deemed exempt by the local institutional review board.

\section{Symptom assessment}

Patients' symptoms were measured with use of the disease specific quality of life questionnaires UDI and DDI. The UDI questionnaire has previously been revised and has been validated for the Dutch language [18]. The original UDI domain structure was developed with data from a highly selective population of higher educated women, aged 45 years or older [19]. The revised UDI can be applied to a broad population of women, and is therefore recommended. This UDI consist of 11 items and five domains on bothersome urogenital symptoms (overactive bladder, urinary incontinence, obstructive micturition, pain, and genital prolapse). Two domains (urinary incontinence and genital prolapse) were used in the study, because only these two urogenital symptoms have been described in relation to perineal descent in the literature [11, 16, 17]. The DDI measures bothersome defecatory symptoms, and consists of 11 items in five domains (constipation, obstructive defecation, pain, incontinence, and flatulence). This questionnaire has been validated, however, has not yet been published. In Appendix A, the questions from the DDI to assess the presence of defecatory symptoms are presented.

Participants were asked whether or not a symptom was present, and in case present, the bother the woman experiences from that symptom. The latter is measured with a four-point Likert scale ranging from not at all to a lot. For factor analysis, the scores of both parts of each question were transformed into $1=$ no symptom; $2=$ symptom present, no bother; $3=$ symptom present, slightly bothersome; 4 = symptom present, moderately bothersome; $5=$ symptom present, greatly bothersome. In calculating domain scores, women not having a symptom or having a symptom without bother are scored equally. The domain scores were transformed into a continuous scale ranging from 0 to 100. A high score on the domain indicates more bothersome symptoms on that particular domain. Therefore, the scores represent both the presence and bother of the symptoms.

\section{Dynamic MR imaging protocol [20-22]}

The dynamic MR imaging was performed with the patient in the supine position with parallel and slightly flexed legs. Patients were requested not to void for $1-2 \mathrm{~h}$ prior to the examination. The rectum was opacified using 100-150 ml ultrasound gel. The urethra, bladder, and vagina were not opacified. No premedication was given. MR images were acquired using a 3 T MR scanner (TIM TRIO, Siemens Medical, Germany) and an eight-channel body phasedarray coil. MR images were obtained in the midsagittal plane using a half-Fourier acquisition single-shot turbo spin-echo sequence $(2000 \mathrm{~ms} / 90 \mathrm{~ms}$ repetition time/ echo time; $150^{\circ}$ flip angle), with a temporal resolution of $1 \mathrm{~s}$ during 2 min. During the MR examination, the patient was asked to relax the pelvic floor muscles, to contract the muscles slowly, relax again, and then to increase the intraabdominal pressure and strain in order to defecate. To assure that the patient followed the instruction given, all images were viewed online on the MR console. A whirl of urine in the bladder and/or a dent into the cranial portion of the bladder indicated adequate straining.

The images were analyzed at a later stage on a console with zoom facilities and electronic calipers. The observer 
was blinded to the patients' symptoms and the clinical findings. The images on maximal strain were used to assess the prolapse.

The perineal position was determined as the perpendicular distance between the pubococcygeal line and the caudal margin of the sphincter ani muscle in centimeters, at rest and during maximal strain (Fig. 1) [17, 23]. The pubococcygeal line was defined as a straight line between the inferior rim of the pubic bone and the last visible coccygeal joint. Perineal mobility was assessed by calculating the difference between the position of the perineum during maximal strain and at rest. The intra- and interobserver reliability of these measurements have shown to be good to excellent, with the exception of the interobserver reliability at rest, which was moderate [20].

\section{Statistical methods}

In this study, the ability of MR imaging measurements to discriminate women with clear symptom from those with no or minor symptoms was assessed. For this purpose, the questionnaire domain scores were dichotomized as follows: 'no and minor symptoms' which are equal to: 'no symptom', 'symptom present, no bother' or 'symptom present, slightly bothersome' (domain score $<33.33$ ) and 'clear symptoms' which are equal to: 'symptom present,



Fig. 1 MR image obtained at rest. Dynamic midsagittal half-Fourier acquisition single-shot turbo spin-echo $\left(2000 / 90 ; 150^{\circ}\right)$ through the pelvis of a 62-year-old woman with symptoms of pelvic organ prolapse. The image shows the measurement of the perineal position in relation to the reference line used. $P C L$ pubococcygeal line moderately bothersome' or 'symptom present, greatly bothersome' (domain score $\geq 33.33$ ), respectively.

Univariate logistic regression was used to study the relationship between the questionnaire domain scores and each of the measurements of the perineal position, (using MR imaging) and the baseline characteristics (i.e., age, BMI, and parity), separately. The dependent variable was the probability that an individual is classified into the highest coded category of a specific domain score (i.e., 'clear symptoms'). The independent variable was one of the MR imaging measurements or one of the baseline characteristics, respectively. The crude odds ratios with $95 \%$ confidence intervals are presented.

Spearman's rank correlation test was used to test the correlation between measurements of the perineal position and age, BMI, and parity for statistical significance. Statistical analyses were performed using SPSS version 16.0 (SPSS, Inc.,Chicago, IL, USA). $P$ values $<0.05$ were considered statistically significant.

\section{Results}

Overall, 700 new patients with urogynecological symptoms were evaluated during the study period. One hundred and twenty women underwent dynamic MR imaging of the pelvic floor. Sixty-nine of these women had completed the questionnaires and was included in the study. There were no statistically significant differences in baseline characteristics such as age, pelvic organ prolapse questionnaire (POP-Q), and number of previous gynecological operations in the women who did and did not return the questionnaires. Women's baseline characteristics, clinical measurements, and dynamic MR imaging measurements are shown in Table 1. All women had at least one vaginal delivery. Ninety percent of the women had a history of one or more gynecological operations, i.e., hysterectomy, POP surgery, or urinary incontinence surgery. There were some negative values of the calculated value of perineal mobility, which were within the range of reproducibility, except for two values which were the result of levator coactivation during straining, and thus perineal elevation.

Table 2 shows the crude odds ratio with 95\% confidence interval, for the probability of symptoms (questionnaire domain scores), of the baseline characteristics (age, BMI, and parity). Only age was statistically significant related to complaints of fecal incontinence $(\mathrm{OR}=1.07,95 \% \mathrm{CI}=1.01-1.13)$.

The Spearman's correlation coefficient between the baseline characteristics (age, BMI, and parity) and the perineal position and mobility was assessed. Aging was statistically significant, but only poorly correlated with the position of the perineum during strain $\left(r_{\mathrm{s}}=-0.29, p=0.01\right)$. 
Table 1 Characteristics of the women included in this study

\begin{tabular}{|c|c|c|}
\hline & $n$ & Median (range) $/ n(\%)$ \\
\hline \multicolumn{3}{|l|}{ Baseline characteristics } \\
\hline Age (years) & 69 & $54(31-75)$ \\
\hline BMI $\left(\mathrm{kg} / \mathrm{m}^{2}\right)$ & 47 & $26(20-36)$ \\
\hline Parity & 65 & $2(1-6)$ \\
\hline Number of previous gynecological operations & 69 & \\
\hline None & & $7(10 \%)$ \\
\hline 1 or 2 operations & & $22(32 \%)$ \\
\hline$\geq 3$ operations & & $40(58 \%)$ \\
\hline Types of gynecological surgery ${ }^{a}$ & 69 & \\
\hline POP surgery & & $34(49 \%)$ \\
\hline Urinary incontinence surgery & & $16(23 \%)$ \\
\hline Hysterectomy & & $39(57 \%)$ \\
\hline \multicolumn{3}{|l|}{ Clinical measurements } \\
\hline POP-Q $(\mathrm{cm})^{\mathrm{b}}$ & 66 & \\
\hline $\mathrm{Ba}$ & & $-2(-3$ to +4$)$ \\
\hline $\mathrm{C}$ & & $-6(-9$ to +3$)$ \\
\hline $\mathrm{Bp}$ & & $0(-3$ to +4$)$ \\
\hline \multicolumn{3}{|l|}{ UDI } \\
\hline Urinary incontinence & 63 & $17(0-100)$ \\
\hline Domain score $<33.33$ & & $35(56 \%)$ \\
\hline Domain score $\geq 33.33$ & & $28(44 \%)$ \\
\hline Genital prolapse & 65 & $33(0-100)$ \\
\hline Domain score $<33.33$ & & $28(43 \%)$ \\
\hline Domain score $\geq 33.33$ & & $37(57 \%)$ \\
\hline \multicolumn{3}{|l|}{ DDI } \\
\hline Constipation & 65 & $17(0-100)$ \\
\hline Domain score $<33.33$ & & $42(65 \%)$ \\
\hline Domain score $\geq 33.33$ & & $23(35 \%)$ \\
\hline Obstructed defecation & 65 & $17(0-83)$ \\
\hline Domain score $<33.33$ & & $46(71 \%)$ \\
\hline Domain score $\geq 33.33$ & & $19(29 \%)$ \\
\hline Pain & 65 & $0(0-100)$ \\
\hline Domain score $<33.33$ & & $43(66 \%)$ \\
\hline Domain score $\geq 33.33$ & & $22(34 \%)$ \\
\hline Fecal incontinence & 66 & $17(0-100)$ \\
\hline Domain score $<33.33$ & & $42(64 \%)$ \\
\hline Domain score $\geq 33.33$ & & $24(36 \%)$ \\
\hline Flatulence & 66 & $33(0-100)$ \\
\hline Domain score $<33.33$ & & $41(62 \%)$ \\
\hline Domain score $\geq 33.33$ & & $25(38 \%)$ \\
\hline \multicolumn{3}{|l|}{ MR imaging measurements $(\mathrm{cm})^{\mathrm{c}}$} \\
\hline Perineal position at rest & 69 & $5.3(2.8-8.5)$ \\
\hline Perineal position during strain & & $7.1(3.5-10.7)$ \\
\hline Perineal mobility ${ }^{\mathrm{d}}$ & & $1.7(-1.1$ to 4.8$)$ \\
\hline
\end{tabular}

$n$ number of patients, $B M I$ body mass index, $P O P(-Q)$ Pelvic

Organ Prolapse (Quantification), $\mathrm{Ba}$ most descended edge on the anterior vaginal wall during strain, $C$ most descended edge of the cervix or vaginal vault during strain, $B p$ most descended edge on the posterior vagina wall during strain, $\mathrm{cm}$ centimeters, UDI Urogenital Distress Inventory, DDI Defecatory Distress Inventory

${ }^{a}$ Patients may have had multiple previous gynecological surgeries

${ }^{\mathrm{b}}$ Relative to the hymen

${ }^{\mathrm{c}}$ Relative to the pubococcygeal line

${ }^{\mathrm{d}}$ Measurement of the perineal position during strain minus the measurement of the perineal position at rest
Table 3 presents the crude odds ratio with 95\% confidence interval for the probability of symptoms (questionnaire domain scores), of the perineal position, perineal mobility, and a history of previous gynecological surgery. Women with a lowered position of the perineum at 
Table 2 The crude odds ratio with $95 \%$ confidence interval, for the probability of symptoms, of the baseline characteristics, with use of univariate logistic regression analyses
$B M I$ body mass index, $n$ number of patients, $O R$ odds ratio, $C I$ confidence interval, UDI Urogenital Distress Inventory, $D D I$ Defecatory Distress Inventory

\begin{tabular}{|c|c|c|c|c|c|c|}
\hline \multirow[t]{2}{*}{ Symptoms } & \multicolumn{2}{|c|}{ Age (years) } & \multicolumn{2}{|c|}{ BMI $\left(\mathrm{kg} / \mathrm{m}^{2}\right)$} & \multicolumn{2}{|c|}{ Parity (number) } \\
\hline & $n$ & OR $(95 \% \mathrm{CI})$ & $n$ & OR $(95 \% \mathrm{CI})$ & $n$ & OR $(95 \% \mathrm{CI})$ \\
\hline \multicolumn{7}{|l|}{ UDI } \\
\hline Urinary incontinence & 63 & $1.01(0.96-1.06)$ & 44 & $1.09(0.90-1.31)$ & 60 & $1.20(0.67-2.17)$ \\
\hline Genital prolapse & 65 & $1.02(0.97-1.07)$ & 45 & $0.95(0.80-1.13)$ & 62 & $1.31(0.71-2.42)$ \\
\hline \multicolumn{7}{|l|}{ DDI } \\
\hline Constipation & 65 & $1.01(0.95-1.06)$ & 46 & $1.04(0.87-1.25)$ & 62 & $1.68(0.88-3.20)$ \\
\hline Obstructed defecation & 65 & $1.00(0.95-1.05)$ & 45 & $0.99(0.83-1.19)$ & 62 & $1.35(0.74-2.44)$ \\
\hline Pain & 65 & $0.98(0.93-1.04)$ & 45 & $0.98(0.81-1.19)$ & 62 & $1.55(0.83-2.89)$ \\
\hline Fecal incontinence & 66 & $1.07(1.01-1.13)$ & 45 & $0.92(0.75-1.13)$ & 63 & $1.17(0.65-2.12)$ \\
\hline Flatulence & 66 & $1.02(0.97-1.08)$ & 45 & $1.15(0.93-1.42)$ & 63 & $1.19(0.58-2.44)$ \\
\hline
\end{tabular}

rest have an increased risk of prolapse symptoms $(\mathrm{OR}=$ $2.15,95 \% \mathrm{CI}=1.18-3.91)$. None of the other UDI or DDI domain scores was associated with the MR imaging measurements. Women with a history of prior gynecological surgery had statistically significant more prolapse symptoms $(\mathrm{OR}=9.81,95 \% \mathrm{CI}=1.11-87.01)$.

Using multivariate logistic regression, none of the baseline characteristics (age, BMI, and parity) showed to be a confounder in the relations afore mentioned.

\section{Discussion}

This observational dynamic MR imaging study reports on the relation between the position and mobility of the perineum and patients' symptoms of pelvic floor dysfunction (i.e., anorectal dysfunction, prolapse, and urinary incontinence) using standardized questionnaires. Only pelvic organ prolapse symptoms at rest were associated with the degree of descent of the perineum. No association was found between perineal descent and symptoms of anorectal and/or urinary incontinence.

The present results are in agreement with earlier studies on symptoms of constipation, rectal or pelvic pain, and urinary incontinence since the vast majority of studies produced evidence for the absence of a statistically significant correlation with perineal descent [8-11, 16, 17]. Previous studies on the relation between perineal descent and fecal incontinence and obstructed defecation were conflicting [9, 10, 12-15]. In our study, we did not find a relation with regards to these symptoms.

The available studies, in which prolapse symptoms in relation to perineal descent had been assessed, have also reported a statistically significant correlation $[11,17]$. In one of these studies, perineal descent had also been assessed with dynamic MR imaging [17]. In accordance

Table 3 The crude odds ratio with 95\% confidence interval, for the probability of symptoms, of the perineal position and mobility (as measured on dynamic MR imaging), and previous gynecological operation with use of univariate logistic regression analyses

\begin{tabular}{|c|c|c|c|c|c|}
\hline Symptoms & $n$ & $\begin{array}{l}\text { Perineal position at } \\
\text { rest }(\mathrm{cm}) \text { OR }(95 \% \mathrm{CI})\end{array}$ & $\begin{array}{l}\text { Perineal position during } \\
\text { strain }(\mathrm{cm}) \text { OR }(95 \% \mathrm{CI})\end{array}$ & $\begin{array}{l}\text { Perineal mobility }{ }^{\mathrm{a}}(\mathrm{cm}) \\
\text { OR }(95 \% \mathrm{CI})\end{array}$ & $\begin{array}{l}\text { Previous operation } \\
\text { OR }(95 \% \mathrm{CI})\end{array}$ \\
\hline \multicolumn{6}{|l|}{ UDI } \\
\hline Urinary incontinence & 63 & $1.16(0.71-1.88)$ & $0.81(0.55-1.19)$ & $0.66(0.41-1.05)$ & $1.68(0.28-9.90)$ \\
\hline Genital prolapse & 65 & $2.15(1.18-3.91)$ & $1.37(0.93-2.06)$ & $0.88(0.57-1.36)$ & $9.81(1.11-87.01)$ \\
\hline \multicolumn{6}{|l|}{ DDI } \\
\hline Constipation & 65 & $1.22(0.70-2.11)$ & $1.23(0.78-1.92)$ & $0.80(0.51-1.27)$ & $0.81(0.14-4.84)$ \\
\hline Obstructed defecation & 65 & $1.51(0.87-2.61)$ & $1.07(0.71-1.62)$ & $1.09(0.68-1.75)$ & $1.11(0.19-6.55)$ \\
\hline Pain & 65 & $0.95(0.57-1.57)$ & $0.92(0.62-1.37)$ & $0.93(0.59-1.47)$ & $1.32(0.23-7.40)$ \\
\hline Fecal incontinence & 66 & $0.72(0.43-1.20)$ & $0.76(0.51-1.14)$ & $0.92(0.59-1.43)$ & $0.49(0.27-8.32)$ \\
\hline Flatulence & 66 & $1.02(0.59-1.77)$ & $0.82(0.53-1.28)$ & $0.76(0.47-1.25)$ & $0.45(0.05-4.02)$ \\
\hline
\end{tabular}

$\mathrm{cm}$ centimeters relative to the pubococcygeal line, $n$ number of patients, $O R$ odds ratio, $C I$ confidence interval, UDI Urogenital Distress Inventory, DDI Defecatory Distress Inventory

${ }^{a}$ Measurement of the perineal position during strain minus the measurement of the perineal position at rest 
with the present study, the pubococcygeal line and the sphincter ani muscle had been used as reference line and measurement point. In contrast, however, Hoyte et al. have reported no significant difference between the measurement of the perineum at rest in patients with and without symptoms of prolapse, but have found a statistically significant difference during straining. We did not find a good explanation for the fact that in the present study, a relation at rest was found, but not at strain, even though the rest and strain measurements were correlated.

The estimated OR for the relation of the perineal position and mobility with pain are all much closer to 1.00 (0.93-0.95) compared to nearly all other symptoms. Therefore, it is unlikely that, in this study, of all symptoms the relation of pain with the perineal position and mobility is of clinically relevance. Although the number of participants in this study is limited, Table 3 shows that this study is large enough to detect an OR of $2.15 / \mathrm{cm}$ increase in perineal position and mobility.

To our knowledge, no previous studies have assessed the patients' BMI in relation to perineal descent. Although a high BMI seems a theoretical risk factor for perineal descent, no association could be established. The same held true for age and parity, although others have previously described a relation with perineal descent for these parameters [3, 4, 7, 24, 25].

We have assessed the agreement between the perineal position during straining and $\mathrm{POP}-\mathrm{Q}$ points $\mathrm{Ba}, \mathrm{C}$, and $\mathrm{Bp}$ [26]. No statistically significant correlation has been found (data not shown). The study was performed in a tertiary referral center. One of the reasons for referral to our center is when there is a discrepancy between symptoms and clinical findings. This implies that patients where POP-Q findings could not explain symptoms were overrepresented. Therefore, this population is very appropriate to assess a relation between symptoms of pelvic floor dysfunction and less obvious measurements such as perineal descent. Even in this population where rare conditions are expected to be overrepresented, perineal descent only showed a limited correlation with symptoms. In our opinion, this shows that the clinical value of this measurement is probably limited.

The observational character of this study is a limitation. Only $60 \%$ of the women who have had dynamic MR imaging investigation of the pelvic floor had returned or completed the questionnaires. Furthermore, MR imaging was performed as part of routine clinical practice in patients with recurrent prolapse, especially in the posterior compartment and consequently these women had only little anterior or apical prolapse.

A shared problem, in the literature and this manuscript, is the lack of a method to objectively assess the effort of strain during MR examination of the pelvic floor. Other methods which have been used in the literature for standardization are the respiratory peak flow meter [27], the reversal of flow in the femoral veins as seen on the axial MR images [28], and repetitive cycles of straining until the degree of protrusion remained constant [29]. Whether one method is preferable is unknown.

We have assessed perineal descent in one direction and in one plane only. It is, however, unknown whether the direction of the movement of the perineum during strain varies and whether perineal bulging was adequately assessed by our measurements. We have not assessed for parallel displacement in relation to the pubococcygeal line, but only the perpendicular one. This might be relevant and thus a limitation of our study. The presence of a levator ani hernia, unilateral, or bilateral, has been described in association with perineal descent [30]. Although the significance of levator ani hernia is unknown, the presence of these hernias has not been assessed in this study. Dynamic MR imaging assessment in the coronal or axial plane may be a valuable adjunct in the evaluation of patients who present with the physical findings of perineal descent. No significant differences in symptoms of anorectal dysfunction, urinary incontinence, and pelvic pain in patients with or without a levator ani hernia, however, have been described thus far [30].

It is furthermore imaginable that the patients' symptoms associated with perineal descent are still undefined, and that the right questions were just not asked. Considerable perineal descent might for example be accompanied by a heavy feeling in the lower abdomen and the pelvic floor. These questions were not represented in the questionnaires and further research is needed in this respect.

In conclusion, only pelvic organ prolapse symptoms were associated with the degree of descent of the perineum, but not the anorectal symptoms and symptoms of urinary incontinence. The clinical impact of perineal descent in urogynecology is still unclear at this time point. In view of our results it seems, however, justified to promote further research with regards to the descending perineum syndrome.

Financial support None.

Conflicts of interest None.

Open Access This article is distributed under the terms of the Creative Commons Attribution Noncommercial License which permits any noncommercial use, distribution, and reproduction in any medium, provided the original author(s) and source are credited. 


\section{Appendix A}

Table 4

Table 4 Defecation distress inventory

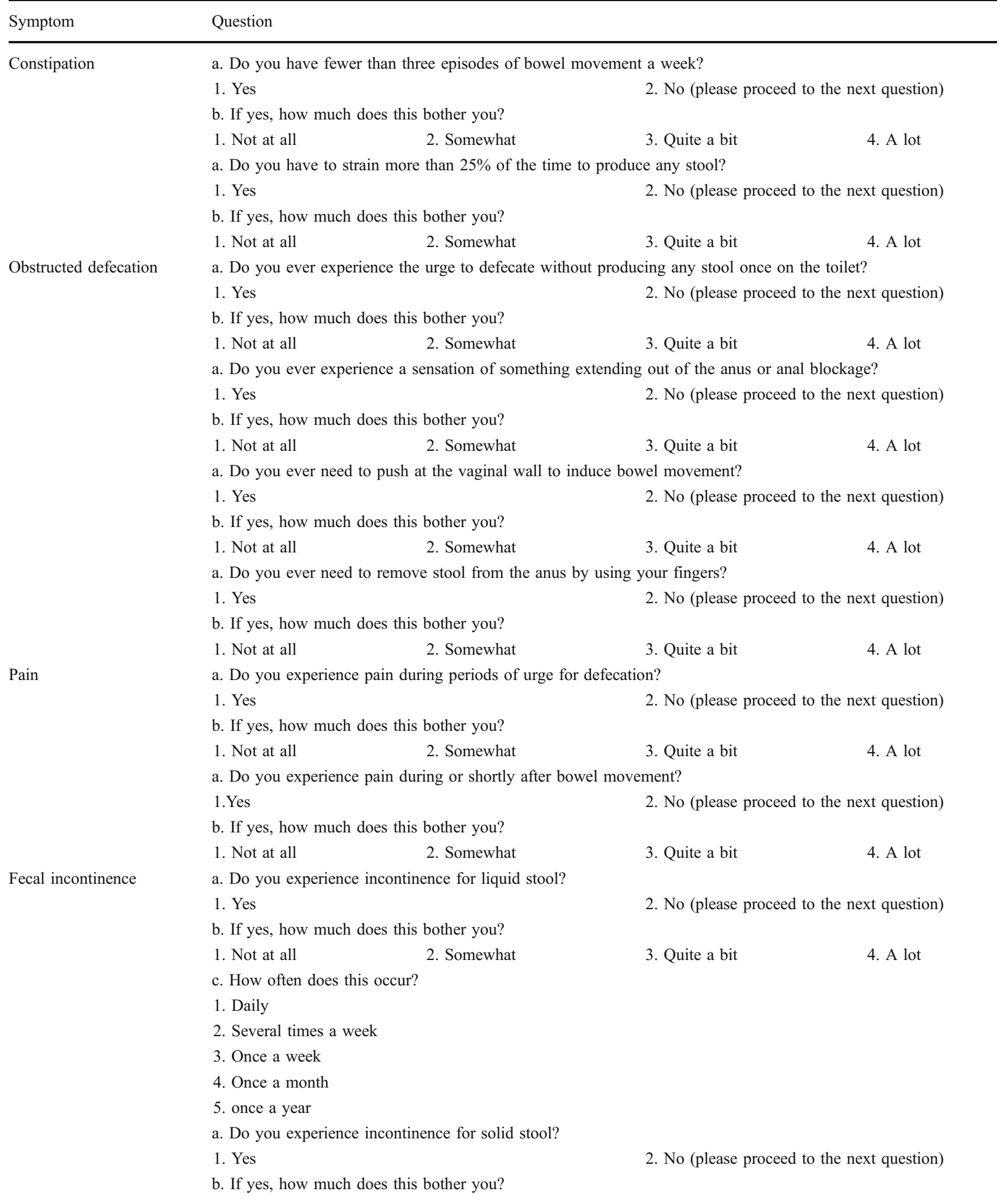


Table 4 (continued)

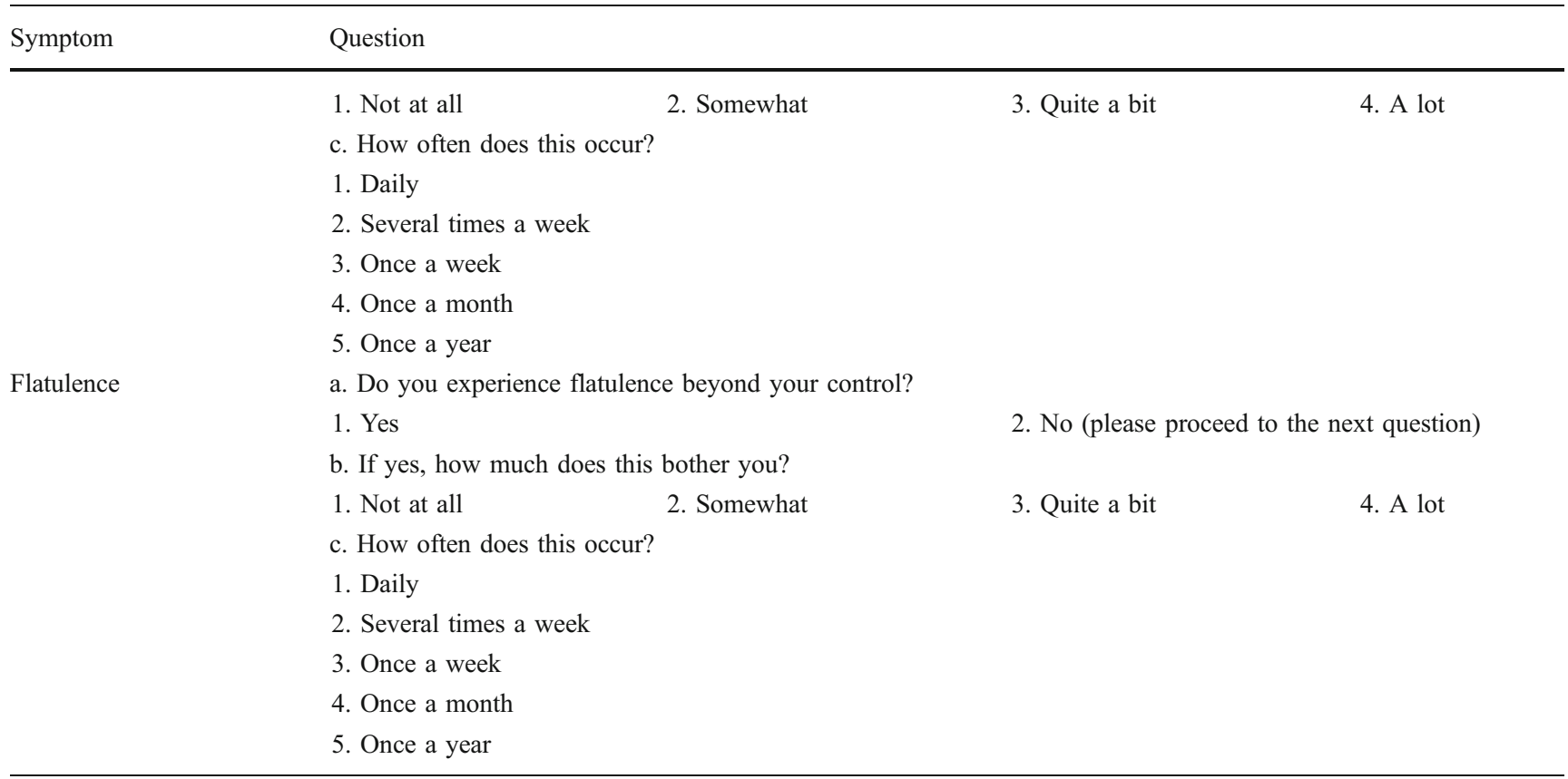

\section{References}

1. Parks AG, Porter NH, Hardcastle J (1966) The syndrome of the descending perineum. Proc R Soc Med 59:477-482

2. Hardcastle JD (1969) The descending perineum syndrome. Practitioner 203:612-619

3. Laurberg S, Swash M (1989) Effects of aging on the anorectal sphincters and their innervation. Dis Colon Rectum 32:737-742

4. Ryhammer AM, Laurberg S, Sorensen FH (1997) Effects of age on anal function in normal women. Int J Colorectal Dis 12:225229

5. Tomlinson BE, Walton JN, Rebeiz JJ (1969) The effects of ageing and of cachexia upon skeletal muscle. A histopathological study. J Neurol Sci 9:321-346

6. Parks AG, Swash M, Urich H (1977) Sphincter denervation in anorectal incontinence and rectal prolapse. Gut 18:656-665

7. Ryhammer AM, Laurberg S, Hermann AP (1996) Long-term effect of vaginal deliveries on anorectal function in normal perimenopausal women. Dis Colon Rectum 39:852-859

8. Bharucha AE, Fletcher JG, Seide B, Riederer SJ, Zinsmeister AR (2005) Phenotypic variation in functional disorders of defecation. Gastroenterology 128:1199-1210

9. Goei R (1990) Anorectal function in patients with defecation disorders and asymptomatic subjects: evaluation with defecography. Radiology 174:121-123

10. Savoye-Collet C, Savoye G, Koning E, Leroi AM, Dacher JN (2003) Defecography in symptomatic older women living at home. Age Ageing 32:347-350

11. Dietz HP, Korda A (2005) Which bowel symptoms are most strongly associated with a true rectocele? Aust $\mathrm{N} \mathrm{Z} \mathrm{J} \mathrm{Obstet}$ Gynaecol 45:505-508

12. Skomorowska E, Hegedus V, Christiansen J (1988) Evaluation of perineal descent by defaecography. Int J Colorectal Dis 3:191-194

13. Snooks SJ, Henry MM, Swash M (1985) Anorectal incontinence and rectal prolapse: differential assessment of the innervation to puborectalis and external anal sphincter muscles. Gut 26:470-476
14. Bartolo DC, Roe AM, Virjee J, Mortensen NJ, Locke-Edmunds JC (1988) An analysis of rectal morphology in obstructed defaecation. Int J Colorectal Dis 3:17-22

15. Lubowski DZ, King DW, Finlay IG (1992) Electromyography of the pubococcygeus muscles in patients with obstructed defaecation. Int J Colorectal Dis 7:184-187

16. Ho YH, Goh HS (1995) The neurophysiological significance of perineal descent. Int J Colorectal Dis 10:107-111

17. Hoyte L, Schierlitz L, Zou K, Flesh G, Fielding JR (2001) Twoand 3-dimensional MRI comparison of levator ani structure, volume, and integrity in women with stress incontinence and prolapse. Am J Obstet Gynecol 185:11-19

18. van der Vaart CH, de Leeuw JR, Roovers JP, Heintz AP (2003) Measuring health-related quality of life in women with urogenital dysfunction: the urogenital distress inventory and incontinence impact questionnaire revisited. Neurourol Urodyn 22:97-104

19. Shumaker SA, Wyman JF, Uebersax JS, McClish D, Fantl JA (1994) Health-related quality of life measures for women with urinary incontinence: the Incontinence Impact Questionnaire and the Urogenital Distress Inventory. Continence Program in Women (CPW) Research Group. Qual Life Res 3:291-306

20. Broekhuis SR, Kluivers KB, Hendriks JC, Vierhout ME, Barentsz JO, Futterer JJ (2009) Dynamic magnetic resonance imaging: reliability of anatomical landmarks and reference lines used to assess pelvic organ prolapse. Int Urogynecol J Pelvic Floor Dysfunct 20:141-148

21. Broekhuis SR, Kluivers KB, Hendriks JC, Futterer JJ, Barentsz JO, Vierhout ME (2009) POP-Q, dynamic MR imaging, and perineal ultrasonography: do they agree in the quantification of female pelvic organ prolapse? Int Urogynecol J Pelvic Floor Dysfunct

22. Broekhuis SR, Futterer JJ, Hendriks JC, Barentsz JO, Vierhout ME, Kluivers KB (2009) Symptoms of pelvic floor dysfunction are poorly correlated with findings on clinical examination and dynamic MR imaging of the pelvic floor. Int Urogynecol J Pelvic Floor Dysfunct 
23. Hsu Y, Summers A, Hussain HK, Guire KE, DeLancey JO (2006) Levator plate angle in women with pelvic organ prolapse compared to women with normal support using dynamic MR imaging. Am J Obstet Gynecol 194:1427-1433

24. Bannister JJ, Abouzekry L, Read NW (1987) Effect of aging on anorectal function. Gut 28:353-357

25. Jameson JS, Chia YW, Kamm MA, Speakman CT, Chye YH, Henry MM (1994) Effect of age, sex and parity on anorectal function. Br J Surg 81:1689-1692

26. Bump RC, Mattiasson A, Bo K, Brubaker LP, DeLancey JO, Klarskov P, Shull BL, Smith AR (1996) The standardization of terminology of female pelvic organ prolapse and pelvic floor dysfunction. Am J Obstet Gynecol 175:10-17

27. Braekken IH, Majida M, Ellstrom-Engh M, Dietz HP, Umek W, Bo K (2008) Test-retest and intra-observer repeatability of two-, three- and four-dimensional perineal ultrasound of pelvic floor muscle anatomy and function. Int Urogynecol J Pelvic Floor Dysfunct 19:227-235

28. Lienemann A, Sprenger D, Janssen U, Grosch E, Pellengahr C, Anthuber C (2004) Assessment of pelvic organ descent by use of functional cine-MRI: which reference line should be used? Neurourol Urodyn 23:33-37

29. Fauconnier A, Zareski E, Abichedid J, Bader G, Falissard B, Fritel X (2007) Dynamic magnetic resonance imaging for grading pelvic organ prolapse according to the international continence society classification: which line should be used? Neurourol Urodyn 27:191-197

30. Gearhart SL, Pannu HK, Cundiff GW, Buller JL, Bluemke DA, Kaufman HS (2004) Perineal descent and levator ani hernia: a dynamic magnetic resonance imaging study. Dis Colon Rectum 47:1298-1304 